\title{
Mathematical Methods for Solar Chimney Analysis
}

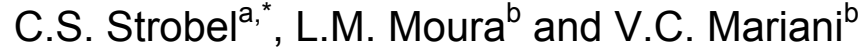 \\ ${ }^{a}$ Mechanical Engineering Department, Federal University of Paraná, Av. Cel. Francisco H. dos Santos, s/n, \\ 81530-900 Curitiba, Brazil \\ ${ }^{b}$ Mechanical Engineering Department, Pontifical Catholic University of Paraná, R. Imaculada Conceição, \\ 1155, 80215-901 Curitiba, Brazil
}

\begin{abstract}
Solar Chimney Power Plants (SCPP) - also known as Solar Updraft Power Plants - consists in a structure composed by a glass collector, placed in a few meters from the ground, with a chimney in its center, in order to promote a pressure differential and consequently a heated air flow. On the bottom of the chimney, a turbine convert the kinetic energy from the heated airflow in electric power. Many mathematical and numerical methods for predict the performance of this kind of renewable energy plant have been conducted, but always with a divergence among them. The main objective of this work is to compare the mathematical methods of evaluation the overall performance, as well to propose a more accurate mathematical method, comparing all results with Manzanares Plant and other methods in the literature. Two approaches were studied and then modified: one based on continuity and momentum equation and the other based on the sum of all pressure drops along the system. The main reasons of the difference between the models analyzed are highlighted. The results shows that one of the proposed methods leads to a divergence of only $1.3 \%$ when compared to Manzanares pilot plant, i.e., with an excellent agreement with experimental data.
\end{abstract}

Keywords: Solar chimney, Solar energy, Renewable energy, Heat transfer, Solar tower.

\section{INTRODUCTION}

Solar chimneys, or updraft towers, are power generation plants which use the thermal energy from the sun to heat the air below a glass collector, and in wich a chimney is installed at its center to promote a air flow by connecting the heated mass of air (with lower density) to a lower pressure region, outside the top of the chimney. This process creates a continuous airflow, and the kinetic energy is then extracted by turbines located at the base of the chimney.

The ground below the chimney stores a fraction of the day energy, and releases this energy during the night, helping to maintain the flow a little longer. The airflow created by the buoyant force is proportional to the increase in air temperature in the collector and the height of the chimney. The power is extracted by one or more turbines, and the total power achieved is proportional to the volumetric flow rate and pressure drop across the turbine.

In 1981, an experimental solar chimney prototype was built in Manzanares, Spain, supported by the German government, with installed capacity of $50 \mathrm{~kW}$ and nominal height of $200 \mathrm{~m}$. Haaf et al. [1] shows in his work the details of operation, cost analysis and energy balances. Once implemented and with data acquired, Haaf [2] presented preliminary results obtained by this prototype, and it demonstrated the feasibility and reliability of the concept of solar chimneys.

*Address correspondence to this author at the Av. Cel. Francisco $\mathrm{H}$. dos Santos, s/n, 81530-900 Curitiba, Brazil; Tel: + 5541 99121-0181; Fax: + 5541 3434-2326; E-mail address: strobel@ufpr.br
After these studies conducted in Manzanares, studies with very different focuses have been conducted to determine the influence of several parameters on output energy and efficiency, as turbine disposal, ground roughness and thermal properties, geometry of the plant, quality of roof material, development and validation of mathematical and numerical models, as well the study of the technical and economic feasibility of the use of this kind of technology in several countries around the world.

Koonsrisuk et al. [3] proposed a different model, which is also discussed in this work, in which the mass flow is determined by the total pressure drops in the system, but simplifies some minor losses and considers the total amount of incident radiation as the heat absorbed by the flow, negleting the heat absorbed by the ground and collector, as well the heat reflected for surroundings, and also does not consider the multiple reflections on the glass cover, and the multiple reflections between the glass cover and the ground, investigated by Strobel et al. [4].

Recently, Fathi et al. [5] conducted an Numerical-analytical assessment on Manzanares prototype, and they reached a $2.52 \%$ of divergence compared with Manzanares experimental results, and Guo et al. [6], using a thermodynamic model, reached $4.85 \%$ of divergence.

Regarding analytical models, Padki and Sherif [7] worked on a set of differential equations to analyze a solar chimney. The analytical model predict the performance with $4 \%$ to $6 \%$ of deviation between the numerical method.

In order to provide detailed information about the Solar Chimney technology, Hussain et al. [8] compiled 
the state of the art for the solar chimney technology, but the don't present the mathematical models for heat transfer coefficients. These mathematical models are presented by Bernardes et al. [9], in which those heat transfer coefficients are detailed.

Among these several works, Bernardes et al. [10] presented a mathematical and numerical model to evaluate the performance of a solar chimney, which agrees with Manzanares data in a high degree; reaching a divergence of $-2.0 \%$ to $1.5 \%$ depending on the simulation day. This model uses the heat transfer analysis in a semi-permanent model to predict the temperature increase provided by the collector and the momentum equation to determine the mass airflow and the power generated. Howerver, do not considers the effect of multiple reflections of the incident radiation in the glass cover and between the collector and the ground. That model, due to the high level of agreement with the experimental data, is used in this study.

The main proposal of this work is simulate and compare the use of multiple reflections on glass cover and on cover/ground interface, in order to improve the accuracy of the original model of the Koonsrisuk et al. [3] and the Bernardes et al. [10]. The original model of Koonsrisuk et al. [3] uses the pressure drops along the ground/collector, chimney and the pressure drop caused by the acceleration below the collector as the airflow moves to the chimney to predict the mass flow rate. That model do not consider the minor pressure drops, as well do not consider the absorption of heat on ground and cover. In particular, the modified model of Koonsrisuk et al. [3], also proposed in this study, includes other losses reported by Von Backström et al. [11] and includes the use of the heat transfer analysis in a semi-permanent scheme to predict the temperature increase, considering the multiple reflections on the collector.

Thus, this study introduces several modifications in models from Bernardes et al. [10] and Koonsrisuk et al. [3] and comparisons between these four models original and modified models - are conducted. The description of the mathematical and numerical approach used in these four models are presented in the second section, as well as the results and discussion about the differences found between the mathematical models when compared to Manzanares data [12] are described in third section. In the last section the main conclusions are presented.

\section{MATHEMATICAL MODEL}

The proposed model considers an unsteady state condition where the working fluid is air, and the flow velocity is a function of the buoyancy force caused by the increase of air temperature in the collector. This analysis must be cautious therefore, as there is the influence of the glass cover and the unsteady conduction in the ground, where both glass and ground absorb a fraction of the heat. The Figure 1 shows a schematic of the airflow in solar chimney.

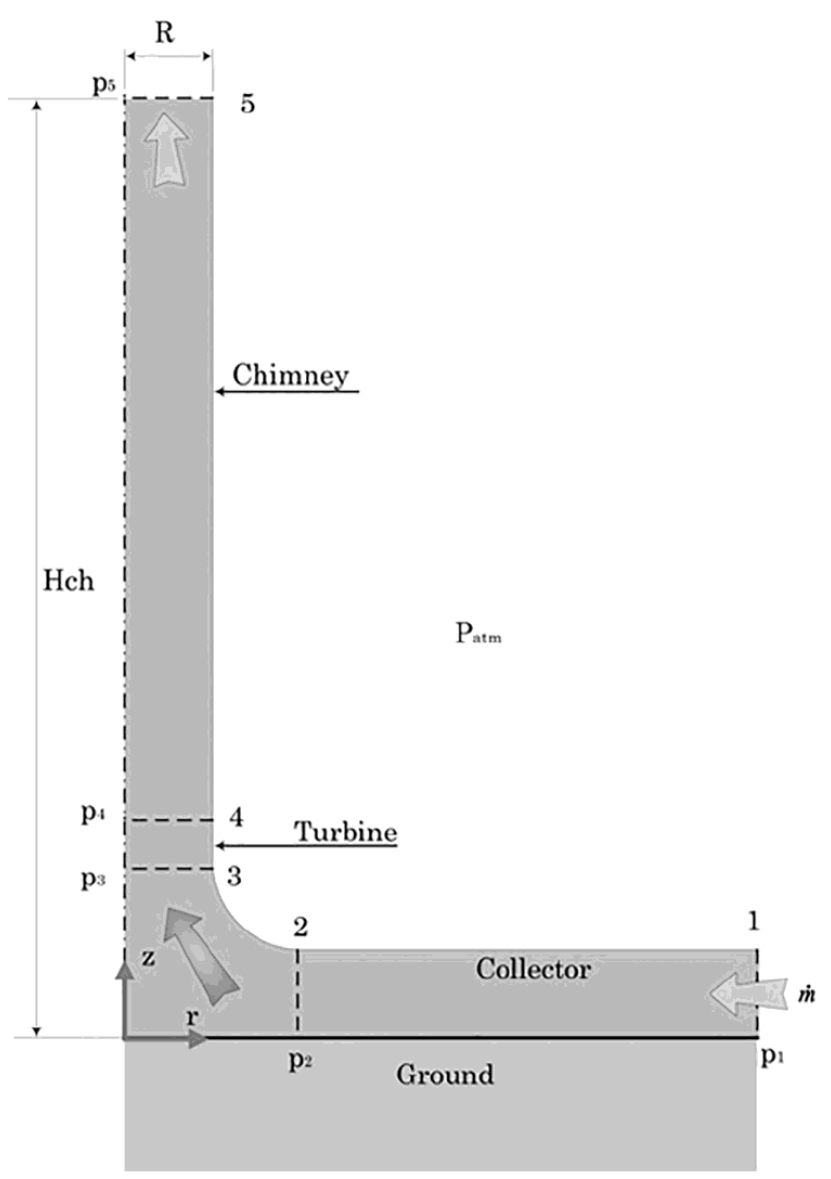

Figure 1: Schematic of the power plant model.

The behavior of the air inside the collector and the chimney was treated considering the following hypothesis:

- The collector has a simple pane of glass;

- The collector is treated as a plane surface;

- $\quad$ The airflow is axisymmetric, i.e., the uneven heat of collector surface related to chimney axis is neglected;

- The height of the collector is set constant above a plane ground;

- $\quad$ The vertical temperature gradient between the ground and the glass cover can be neglected.

Increase of Temperature Provided by the Collector

A solar chimney with a single glass coverage collector, has an energy flow as shown in Figure 2. 


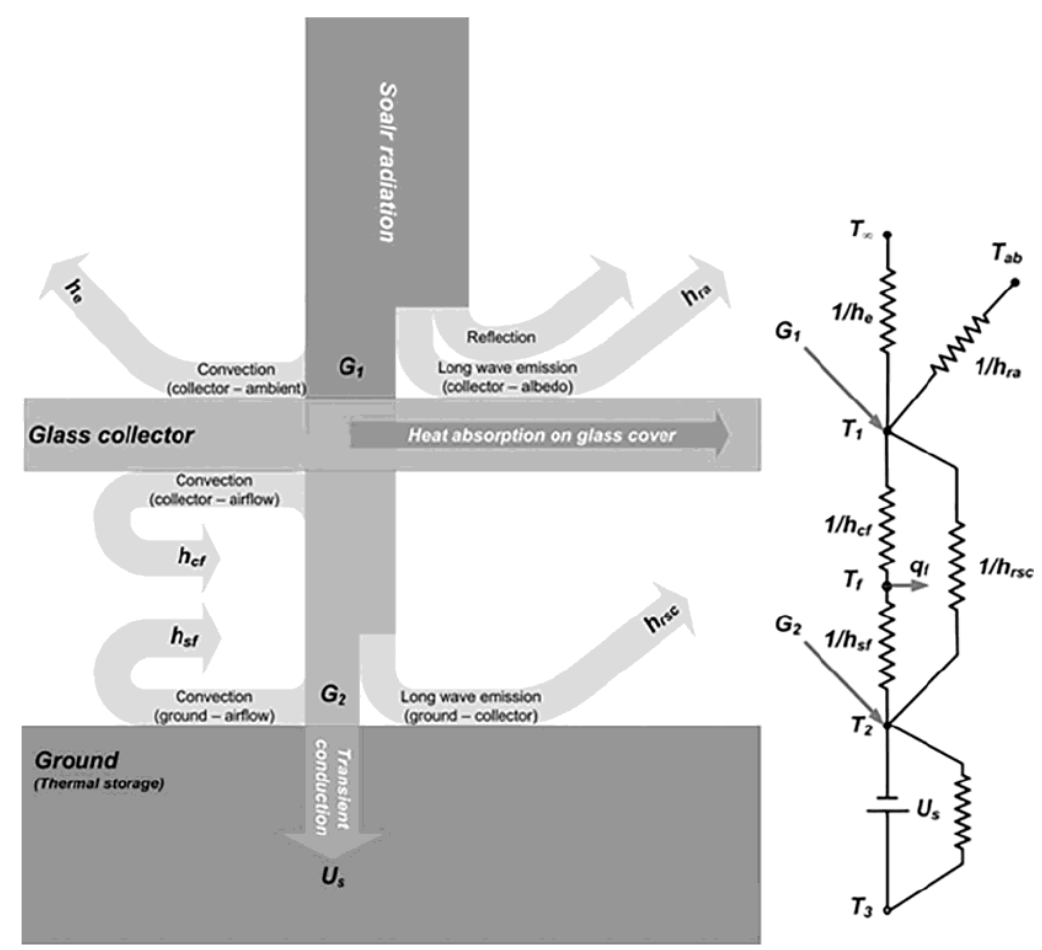

Figure 2: Thermal network on interface ground/collector and thermal resistances.

The radius of the collector is divided in a finite number of sections, where each section can be analyzed individually. For each intermediate node an energy balance in steady state condition for a given time was made, resulting in the following equations:

$T_{1}: G_{1}+h_{r s c}\left(T_{2}-T_{1}\right)+h_{c f}\left(T_{f}-T_{1}\right)=h_{e\left(T_{1}-T_{\infty}\right)}+$ $h_{r a}\left(T_{1}-T_{a b}\right) \quad$ Eq. 1

Where $T_{1}$ is the temperature of the glass collector; $G_{1}$ is the incident radiation from the sun in the collector; $h_{r s c}$ is the radiative heat transfer coefficient between the ground and the collector; $T_{2}$ is the temperature of the ground surface; $T_{f}$ is the temperature of the air between the collector and the ground; $h_{c f}$ is the convective heat transfer coefficient of the air between the collector and the heated airflow; $h_{e}$ is the convective heat transfer coefficient between the collector and the external environment; $T_{\infty}$ is the ambient temperature; $h_{r a}$ is the radiative heat transfer between the collector and the albedo; and $T_{a b}$ is the surrounding temperature.

$T_{f}: h_{c f}\left(T_{1}-T_{f}\right)=h_{s f}\left(T_{f}-T_{2}\right)+q_{f}$

Eq. 2

Where $h_{s f}$ is the radiative heat transfer coefficient between the heated airflow and the ground surface; and $q "$ is the heat flow absorbed by the airflow.

$T_{2}: G_{2}=h_{s f}\left(T_{2}-T_{f}\right)+h_{r s c}\left(T_{2}-T_{1}\right)+U_{s}\left(T_{2}-T_{3}\right) \quad$ Eq. 3

Where $G_{2}$ is the net radiation that passes through the glass collector and reaches the ground surface; $U_{s}$ is the unsteady heat transfer coefficient between the ground surface and the ground interior; and $T_{3}$ is the temperature of the ground surface in the previous time step, $T_{2,0}$.

Considering $U_{e}=h_{\mathrm{e}}+h_{\mathrm{ra}}$, as global heat transfer coefficient external to the collector, and rearranging the terms, the Eqs. (1) to (3) become:

$\left(U_{e}+h_{c f}+h_{r s c}\right) T_{1}-h_{c f} T_{f}-h_{r s c} T_{2}=G_{1}+h_{e} T_{\infty}+$ $h_{r a} T_{a b}$

$h_{c f} T_{1}-\left[h_{c f}+h_{s f}+\left(\frac{\dot{m} c_{p}}{\pi r L}\right)\right] T_{f}+h_{s f} T_{2}=-\left(\frac{\dot{m} c_{p}}{\pi r L}\right) T_{f, e}$ Eq. 5

$-h_{r s c} T_{1}-h_{s f T_{f}}+\left(h_{s f}+h_{r s c}+U_{s}\right) T_{2}=G_{2}+U_{s} T_{2,0}$ Eq. 6

That could be written in a matricial form and the temperature array can be determined by matrix inversion. Note that $\dot{m}$ is the mass flow rate of the heated airflow; $c_{p}$ is the specific heat of the airflow; $r$ is the average radius of the collector node; $T_{f, e}$ is the exit fluid temperature of the section, and $L$ is the section lenght. The product $\pi r L$ is the area of the section in which the radiation acts.

\section{Optical Properties and Heat Transfer Coefficients}

One of the objectives of this work is to include the multiple reflections on the glass cover and on the space between the ground and collector, to modify the original models of Bernardes et al. [10] and the original Koonsrisuk et al. [3] model with this approach.

The incident radiation is subjected to multiple reflections in semitransparent materials, according to Siegel and Howell [13]. However, the ground reflects 
radiation as well, creating multiple reflections between the ground and the glass cover, and the beam reflected by the ground generates more multiple reflections on glass cover. This process repeats itself until the extinction of the radiation beam.

To close the series found both in reflection, absorption and transmission of the system, the series theory is used, resulting in a total portion reflected by collector as:

$R_{s y s}=R_{v}+\left[\frac{\rho_{s} T_{v}^{2}}{1-\rho_{s} R_{v}}\right]=\frac{R_{v}\left(1-\rho_{s} R_{v}\right)+\rho_{s} T_{v}^{2}}{1-\rho_{s} R_{v}}$

Where $R_{\text {sys }}$ is the fraction of the solar radiation reflected by the collector/ground assembly; $R_{v}$ is the fraction reflected by the glass system considering multiple reflection only in the glass; $\rho_{s}$ is the ground reflectivity; and $T_{v}$ is the fraction transmitted by the glass considering only the glass cover.

The total fraction absorbed by the glass collector is:

$A_{s y s}=A_{v}+\frac{\rho_{s} T_{v} A_{v}}{1-\rho_{s} R_{v}}$

Where $A_{v}$ is the fraction absorbed by the glass considering the multiple reflections only in the glass cover. Finally, the total fraction transmitted to the ground is:

$T_{s y s}=T_{v}+\frac{\rho_{s} T_{v} R_{v}}{1-\rho_{s} R_{v}}=\frac{T_{v}\left(1-\rho_{s} R_{v}\right)+\rho_{s} T_{v} R_{v}}{1-\rho_{s} R_{v}}$

According to Strobel et al. [4], the error by not using the appropriate methodology shown previously could vary from $58 \%$ for ground with high reflectance and could reach $85 \%$, depending of the quality of the glazing used and the reflectance of the ground.

The convective and radiation heat transfer coefficients used in this approach rely on the temperature and properties of air and the environment. All these coefficients are described in the work conducted by Hussain et al. and are commonly found in literature.

\section{Models}

The original model of Bernardes et al. [10] has the following incidence of solar radiation on glass cover and on ground, respectively:

$$
\begin{aligned}
& G_{1}=G \\
& G_{2}=G \tau
\end{aligned}
$$

Where $G$ is the incident radiation from the sun and $T$ is the transmissibility of the cover material.

The chimney is modeled on the hypothesis that the flow at its interior is upward, one-dimensional. Its large diameter reduces the pressure drop due to friction, and allows the use of Euler's equation, enabling the measurement of the maximum speed that can be obtained with the increase in temperature in the collector.

The tower (chimney), converts the heated flow from the collector in kinetic energy and potential energy (pressure drop in the turbine). Thus, the increase of air temperature inside the collector acts as a driving force, as it's reduce the density. The less dense air in the base of the chimney is connected with the neighboring atmosphere at the top of the chimney, and thus acquires buoyancy. In this way, the Bernardes et al. [10] model uses the following expression for the real velocity of the airflow at the chimney, considering the effect of pressure drop on the turbine:

$\omega=\sqrt{\frac{2 g H_{c h}\left(T-T_{\infty}\right)(1-x)}{T_{\infty}}}$

Where $g$ is the acceleration of gravity, $H_{c h}$ is the chimney height, $T$ is the temperature at the bottom of the chimney, $T_{\infty}$ is the ambient temperature and the $x$ is the pressure drop factor inside the turbine, considered 0.8 as recommended by Bernardes et al. [10].

The original model presented by Koonsrisuk et al. [3] is based on the sum of the pressure drops: under the collector, due to acceleration resulting from the reduction of area under the collector and in the chimney. As the authors did not consider the pressure drop on the turbine, the current velocity will be the maximum velocity, without the turbine effect. The authors also simplify the amount of heat absorbed by the airflow with a hypothesis that all the horizontal global radiation is absorbed by the flow. The total pressure difference obtained by the heating of the air inside the chimney is:

$\Delta P=\rho g H_{c h} \beta\left(T-T_{\infty}\right)$

Eq. 13

Note that $\beta$ is the thermal expansion coefficient, or $1 / T_{\infty}$.

This difference must be equal to the sum of the total pressure drops throughout the system. According to Koonsrisuk et al. [3], the total pressure drops in the system occurs from collector, area reduction and the chimney, and, after an algebraic manipulation, the maximum velocity of the air flow becomes:

$\omega_{\text {max }}=\sqrt{\frac{g H_{c h}\left(T-T_{\infty}\right)}{T_{\infty}\left(\frac{f_{y} H_{c h}}{R}+\frac{f_{x} R^{4}}{4 h^{3} D_{c}}+\frac{8 R^{4}}{D_{c}^{4}}\right)}}$

In this model, $f_{x}$ is the friction coefficient in the horizontal direction (below the collector), $f_{y}$ is the friction factor in the vertical direction (inside the 
chimney), $D_{c}$ is the outer diameter of the collector and $R$ is the radius of the chimney.

For Koonsrisuk et al. [3] model, the power $\dot{\boldsymbol{W}}$ is the product of the area, velocity and the total pressure drop in the system.

$\dot{W}=\left(\frac{\pi D_{c}^{2}}{4}\right) \omega_{\max } \Delta P$

Where, according to Koonsrisuk et al. [3], the total pressure gradient is the sum of the collector pressure drop, the chimney pressure drop and the pressure drop due the fluid acceleration toward the chimney inside the collector.

$\Delta P=\frac{f_{x} R \rho}{2 h}\left(\frac{\dot{m}}{\rho 2 \pi R h}\right)^{2}+\frac{f_{y} 2 H \rho}{D_{c}}\left(\frac{4 \dot{m}}{\rho \pi D_{c}^{2}}\right)^{2}+2 \rho\left(\frac{2 \dot{m}}{\rho 2 \pi D_{c}^{2}}\right)^{2}$ Eq. 16

Where $f_{x}$ and $f_{y}$ are the friction factors for the collector and for the chimney, respectively, and $R$ is the radius of the chimney.

One of the proposed models for the analyses, is the same proposed by Bernardes et al. [10], however, with changes in the optical behavior on the interface glass and ground. The model follows the same, with a difference in the heat absorbed by the collector and transmitted to the ground, given by the Eqs. (8) and (9), respectively. So, the constants that are multiplied by the solar radiation become:

$$
\begin{array}{ll}
\boldsymbol{G}_{\mathbf{1}}=\boldsymbol{G} & \text { Eq. } 17 \\
\boldsymbol{G}_{\mathbf{2}}=\boldsymbol{G} \boldsymbol{T}_{\text {sys }} & \text { Eq. } 18
\end{array}
$$

Other model proposed in the present work is a variation of the Koonsrisuk et al. [3] model, with the same approach aforementioned regarding the multiple reflections and with other minor pressure drops. As in the work carried out by Von Backström et al. [11], there are other losses in the system, not accounted for by Koonsrisuk et al. [3], in which the authors reported the same in the form of an increase in factor of pressure drop in the turbine. Among other smaller losses, they include in their work: transition collector - chimney, chimney outlet, internal brackets, and non-adiabatic atmosphere, generating a total increase in factor of pressure drop in the turbine to the order of 0.97 , consistent with that suggested by current literature. Without this increase, the expected velocity of the airflow is high, as they do not possess all the pressure drops that really happens. These increases in factor of pressure drop in the turbine cause a fall in velocity within the chimney, arriving at more realistic values. Prior to this approach, the factor considered was 0.8 , as recommended by the literature.

It is known that the power produced by a flow machine, like as Bird et al. [14], is given by the product of pressure drop and volumetric flow rate, in the turbine and its efficiency, resulting in:

$$
\dot{W}=\rho A \sqrt{2\left(\frac{g H_{c h}\left(T-T_{\infty}\right)}{T_{\infty}}\right)^{3}} \eta_{t u r b} x \sqrt{1-x} \quad \text { Eq. } 19
$$

\section{NUMERICAL RESULTS AND DISCUSSION}

The properties of the ground, glass cover and location (latitude and longitude) for the Manzanares region, in order to compare the mathematical models

\begin{tabular}{|c|c|c|}
\hline Parameter & Value & Units \\
\hline Collector height & 2.0 & $\mathrm{~m}$ \\
\hline Collector diameter & 244.0 & $\mathrm{~m}$ \\
\hline Chimney diameter & 10.0 & $\mathrm{~m}$ \\
\hline Chimney height & 194.0 & $\mathrm{~m}$ \\
\hline Glass extinction coefficient & 32.0 & $\mathrm{~m}^{-1}$ \\
\hline Ground and glass cover emissivity & 0.9 & - \\
\hline Thermal conductivity of ground & 0.6 & $\mathrm{~W} \cdot \mathrm{m}^{-1} \cdot \mathrm{K}^{-1}$ \\
\hline Thermal diffusivity of ground & $2.91 \times 10^{-7}$ & $\mathrm{~m}^{2} \cdot \mathrm{s}^{-1}$ \\
\hline Factor of pressure drop on turbine & 0.8 & - \\
\hline Location & Manzanares, Spain & - \\
\hline Latitude / Longitude & 39.03 (North) / 3.14 (West) & $\circ$ \\
\hline Date & $06 / 08 / 1987$ & - \\
\hline Maximum error & 0.01 & $\%$ \\
\hline Number of sections & 2000 & - \\
\hline Time step & 600 & $\mathrm{~s}$ \\
\hline
\end{tabular}
with the experimental data obtained in the same location, are shown in Table 1.

Table 1: Simulation Parameters for Manzanares Pilot Plant 


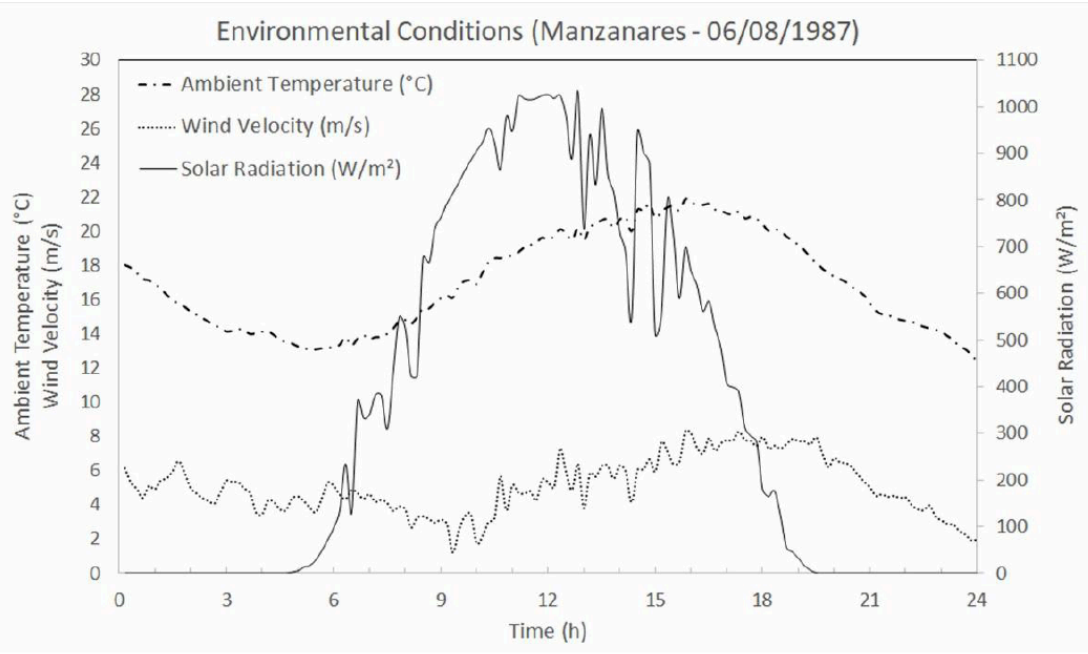

Figure 3: Environmental conditions for the simulation day in Manzanares.

Weinrebe [12] provided the experimental data of Manzanares. Those data is of extreme importance to the proposal of this study, given the need of validation and comparison of the models proposed in this work. In addition, the input data of temperature, horizontal global solar radiation, relative humidity and the ambient air velocity were also provided, and was used in the simulations. Figure 3 shows the profile of the Solar radiation, ambient temperature and wind velocity for $06 / 08 / 1987$ in Manzanares, Spain, data used in this simulation.

The power generation for the Koonsrisuk et al. [3] model was in the order of $194.8 \%$, as shown in Figure 4 and described in Table 2. This is explained by the several head losses not being considered, as mentioned before. Beyond this, this model also considers the hypothesis that all the solar radiation is absorbed by the airflow, and no turbine provides a pressure drop for extracting power, elevating the maximum velocity and the power output estimative.
Modified Koonsrisuk et al. [3] model has a smaller error compared to experimental data of Manzanares, as shown in Figure $\mathbf{4}$ and described by the values in Table 2 , with an error of $37.4 \%$, due to other smaller head losses still not being taken into account, and there is no work in the literature that provides these minor losses for this application. One is the head loss on the structure that supports the glass collector, which generates a pressure drop. A future work must be carried out to predict the drag in each pillar, and consequently the head loss in it.

In the other way, the model proposed by Bernardes et al. [10] obtained a very good approximation to the experimental results of Manzanares, which justifies the use of the model with a good fit, as can be seen in Figure $\mathbf{4}$ and its values in Table 2, leading to an error of only $-1.6 \%$. The modified model of Bernardes et al. [10], using optical properties that consider the effects of multiple reflections in glass cover material and glass/ground interface, led to even more accurate

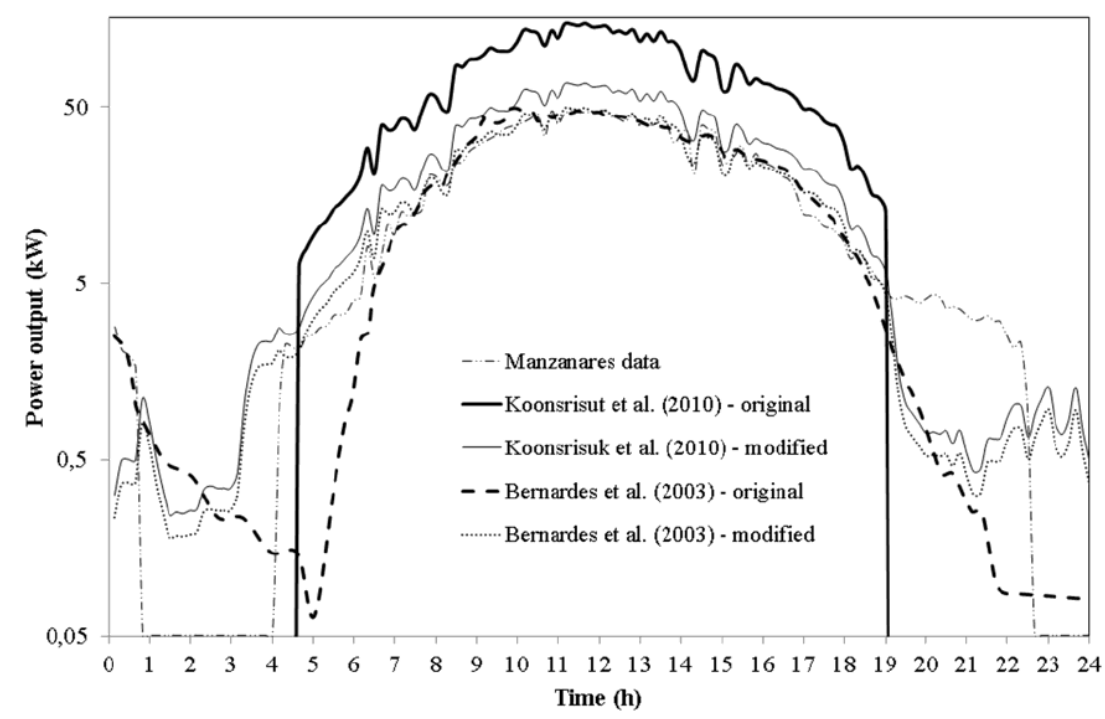

Figure 4: Power output for each model. 
Table 2: Results for Power Output of each Model

\begin{tabular}{|c|c|c|}
\hline Method & Energy output (kWh) & Divergence (\%) \\
\hline \hline Manzanares & 367.25 & (Standard value) \\
\hline Bernardes et al. (2003) - Original & 360.70 & -1.6 \\
\hline Bernardes et al. (2003) - Modified & 372.02 & 1.3 \\
\hline Koonsrisuk et al. (2010) - Original & 1082.51 & 194.8 \\
\hline Koonsrisuk et al. (2010) - Modified & 504.51 & 37.5 \\
\hline
\end{tabular}

results, as can be seen in Figure $\mathbf{4}$ and Table 2, generating an error of $1.3 \%$ when compared to the standard data of experimental setup of Manzanares.

Both models of Koonsrisuk et al. [3] are interesting, but deserve a more in-depth study of all the variables involved, which as of yet are still not fully addressed by the literature. The model of Bernardes et al. [10], original and modified, delivers more reliable results for estimating the power generation, with a divergence from the experimental model of Manzanares in the order of $-1.6 \%$ and $1.3 \%$ respectively.

The power generated in night hours, where no solar radiation affects the power plant, change according the models. The original Koonsrisuk et al. [3] model don't have any power generated, because the solar radiation is the driving force. The other models have a difference, including from each other, due to different temperature field in every time step, in which the subsoil temperature, and consequently the heat transfer through/from the ground is considerably affected.

The model of Bernardes et al. [10] lead to an more accurate result, because the majority of the variables have appropriate correlations for the mathematical and numerical methods. The Koonsrisuk et al. [3] model have too many uncertainties, which turns the mathematical method not reliable with the information used.

Note that there is no data about the uncertainties of measurements performed in Manzanares. Therefore, the hypotheses from the measured results from Manzanares are considered like reference.

\section{CONCLUSION}

This paper proposed the mathematical models analyses of Bernardes et al. [10] and Koonsrisuk et al. [3] comparing them with the experimental prototype of Manzanares, in addition to two other models, based on the former two, and modified in this work to verify improvement points and convergence in the results. Despite the original and modified models of Bernardes et al. [10] having a very small margin of error, to the order of $-1.6 \%$ and $1.3 \%$, respectively. Besides the
Bernardes et al. [10] has already reach a very close result, the difference between these two models is $2.9 \%$, i.e., it is clear that a more accurate method can help to get closer to the reality. Recently, Fathi et al. [5] and Guo et al. [6] conducted an Numerical-analytical assessment on Manzanares prototype, and they reached a $2.52 \%$ and $4.85 \%$, respectively, of divergence compared with Manzanares experimental results, showing that the proposed model are very promissing for future simulations. The original and modified Koonsrisuk et al. [3] models having a much larger discrepancy in the order of $194.8 \%$ and $37.4 \%$, respectively. This does not mean that the work of Koonsrisuk et al. [3] should be ignored. On the contrary, it means that a new approach was launched by the authors, leaving a margin for future studies on pressure drops in this type of structure, so as to improve the models accuracy.

\section{ACKNOWLEDGMENTS}

We would like to thank Dr. Weinrebe, for providing the data from his team in Manzanares, Spain, necessary for validation and comparison of the models analyzed in this work, and Dr. Marco Aurélio Bernardes, for providing the data of his work, also necessary for the comparison of the models. This paper is based on a previous version [15] with preliminary results, published in the annals of the Brazilian Congress of Thermal Sciences and Engineering - ENCIT 2012, organized by the Brazilian Society of Mechanical Sciences and Engineering.

\section{REFERENCES}

[1] Haaf W, Friederich K, Mayr G, Schlaich J. Solar Chimneys Part I: Principle and Construction of the Pilot Plant in Manzanares. International Journal of Solar Energy 1983; 2(1): 3-20. https://doi.org/10.1080/01425918308909911

[2] Haaf W. Solar Chimneys. International Journal of Solar Energy 1984; 2(2): 141-161. https://doi.org/10.1080/01425918408909921

[3] Koonsrisuk A, Lorente S, Bejan A. Constructal solar chimney configuration. Int J Heat Mass Transf 2010; 53(1-3): 327-333. https://doi.org/10.1016/j.jheatmasstransfer.2009.09.026

[4] Strobel C, Moura LM, Mariani VC. Radiative heat transfer considering the effect of multiple reflections in greenhouse structures. J Brazilian Soc Mech Sci Eng 2016; 38(4). https://doi.org/10.1007/s40430-015-0466-6 
[5] Fathi N, Aleyasin SS, Vorobieff P. Numerical-analytical assessment on Manzanares prototype. Appl Therm Eng 2016; 102: 243-250.

https://doi.org/10.1016/j.applthermaleng.2016.03.133

[6] Guo P, Wang Y, Li J, Wang Y. Thermodynamic analysis of a solar chimney power plant system with soil heat storage. Appl Therm Eng 2016; 100: 1076-1084.

https://doi.org/10.1016/j.applthermaleng.2016.03.008

[7] Padki MM, Sherif SA. On a simple analytical model for solar chimneys. Int J Energy Res 1999; 23(4): 345-349. https://doi.org/10.1002/(SICl)1099-114X(19990325)23:4<34 5::AID-ER485>3.0.CO;2-Z

[8] Al-kayiem $\mathrm{HH}$, Chikere O. Historic and recent progress in solar chimney power plant enhancing technologies. Renew Sustain Energy Rev 2016; 58: 1269-1292. https://doi.org/10.1016/j.rser.2015.12.331

[9] Bernardes MAS, Von Backström TW, Kröger DG. Analysis of some available heat transfer coefficients applicable to solar chimney power plant collectors. Sol Energy 2009; 83(2): 264-275.

https://doi.org/10.1016/j.solener.2008.07.019
[10] Bernardes MA, VOß A, Weinrebe G. Thermal and technical analyses of solar chimneys. Sol Energy 2003; 75(6): 511-524.

https://doi.org/10.1016/j.solener.2003.09.012

[11] von Backström TW, Kirstein CF, Pillay LA. The influence of some secondary effects on solar chimney power plant performance. R D J 2006; 1(22): 5-10.

[12] Weinrebe G. Personal letter to author. Stuttgart, Germany, 2010; pp. 1-1.

[13] Siegel R, Howell JR. Thermal Radiation Heat Transfer, 2002; 1.

[14] Bird RB, Stewart WE, Lightfoot EN. Transport Phenomena, 2nd ed. Wiley, 2007.

[15] Strobel C, Moura LM, Mariani VC. Improved model for solar chimney analysis, in ENCIT Brazilian Congress of Thermal Sciences and Engineering, 2012. 